\title{
Exploration and Practice of Talent Cultivation Reform Mode in the Measurement \& Control Technology and Instrument Specialty of Local Agricultural Universities
}

\author{
Liu Yuan, Wu Haiyun, Wei Yong, Bao Zhenbo \\ College of Engineering and Technology \\ Tianjin Agricultural University \\ Tianjin, China \\ 1417325528@qq.com
}

\begin{abstract}
The talent cultivation mode of innovation and entrepreneurship is the inherent requirement to realize the transformation and development of local universities and improve the quality of applied talent cultivation. Aiming at the problems of the separation of education and production in the agricultural engineering of the local agricultural college, and the lagging of the course content in the development of the industry, as well as combining the characteristics of local economic development, this paper sets up a goal of scientific talent cultivation, builds up a new talent cultivation operation mode and puts into practice accordingly, at the same time, provides reference for local undergraduate innovative talent cultivation.
\end{abstract}

Keywords-local agricultural universities; innovation and entrepreneurship; talent cultivation mode; exploration and practice

\section{PROBLEMS IN ENGINEERING SPECIALTY OF LOCAL AGRICULTURAL UNIVERSITIES}

At present, employment of students in agricultural universities is not optimistic, with employment rate being $98 \%$ 5 years ago but being $86 \%$ in 2016, and the number of students engaged in the professional work is decreasing. The reason is the gap between education and industry is more serious, the school talent has been not suitable for the development of society. On one hand, it is not easy for recruitment unit to recruit university students who can meet job requirement. On the other hand, university students can't find jobs which are suitable for professional development. As a result, they loss confidence and interests in their study. Through the study, we found that there are several aspects of restricting talent cultivation. First of all, model of the professional orientation, training objectives and talent cultivation has not met the needs of society. Secondly, it is necessary to adjust not only the teaching system, teaching mode and method, but also teaching staff. For traditional mode, the teaching system focus on theory but not emphasize on practice[1], so that the students loss their interests. However, the teachers, especially the young teachers, are mostly the research scholars graduated from the universities, who have no experience in production and lack of practical experience. And the content of the course lags behind the development of the industry[2].Furthermore, the assessment of

Innovation and Entrepreneurship Training Reform Model Projects of Tianjin Agricultural University (20170813,20170201,20170416) the education quality, is still based on the theoretical assessment mostly, but practice supplemented, which did not focus on the evaluation of students' comprehensive ability. In view of the above problems, this paper probes into the reform of the talent cultivation mode of measurement \&control technology and instrument. We are positioning for the application of professional, innovative and entrepreneurial talent cultivation mode.

\section{RESEARCH ON THE TALENT CULTIVATION OPERATION MODE OF INNOVATION AND ENTREPRENEURSHIP}

Research on the talent cultivation operation mode of innovation and Entrepreneurship Through literature research, research on the talent cultivation mode of local engineering specialty universities for innovation and entrepreneurship education, can be divided into four types of innovative talent cultivation mode: "research experimentation area construction" and "incubator" and "discipline event", "school enterprise cooperation [3]".

The local university innovation and professional operation mode has more than one type to run. From different dimensions, it can be divided into a variety of models, such as innovation and entrepreneurship practice base as the carrier, innovation and entrepreneurship credits for drivers, as well as incentive measures to the system for the mechanism of a variety of operation modes. No matter what type it is, they are in reference to the training mode of basic domestic key universities, to cultivate the social development needs of talent oriented, to construct the training mode of innovative talents. That is, it is the development and innovation on the basis of absorbing the innovation and entrepreneurship training mode and the experience of similar universities. According to the professional advantages and characteristics, studying on the teaching concept, teaching system, curriculum, teaching construction, teaching methods and laboratory construction, and aiming at the application of Tianjin urban modern agriculture talents demand, to improve the personnel ability and quality training as the key point, we put forward the "focusing on students, specializing teaching, paying equal attention to practice teaching and theory teaching, 
experimenting skill training and creative thinking training at the same time"[4]. "Specializing teaching" depends on the guidance ideology and orientation of Tianjin Agricultural University, which "coastal city services culture of modern agriculture, greats consciousness, innovative spirit and entrepreneurial ability, called "three innovation and one basis". On the theory of Constructivism under the guidance, it takes the teacher as the guidance, takes the student as the center, on the basis of the theoretical study, to cultivate students' practical ability and innovation ability as the goal, focus on students' practical skills, scientific thinking, team consciousness and the cultivation of innovation spirit, improve the students' innovation ability and the ability of sustainable development.

\section{FORMULATING THE GOAL OF SCIENTIFIC TALENT CULTIVATION ACCORDING TO HE CHARACTERISTICS OF LOCAL ECONOMIC DEVELOPMENT[5]}

\section{A. Talent cultivation objectives}

According to the positioning of urban modern agriculture in Tianjin City, precision instruments measurement \& control specialty major aims to cultivate a solid professional foundation, strong practice ability, a pioneering and innovative spirit, to have the basic knowledge and application ability.

The application of engineering specialty and technical talents can be engaged in the measurement \& control specialty of various sectors of the national economy, especially in the agricultural sector, to do the jobs related to technology, equipment and systems maintenance, science and technology develop application research.

\section{B. Talent cultivation specifications}

On the aspect of training specifications, re-adjust the professional knowledge and ability. Aiming at the development direction of advanced intelligent agriculture, on the basis of strengthening the basic knowledge, strengthen the professional education, improve the professional skills, and build the knowledge, ability and quality system of applied talents. Set the part of curriculum adjustment, adding features of training modules, using emphasize engineering specialty consciousness and basic skills, with machine, electricity, computer professional knowledge as the support, taking the humanities and Social Sciences, computer and foreign language as the cornerstone, constructing a full range of training framework based on morality, technology, engineering specialty ability, humanities and communication.

\section{EXPLORATION AND PRACTICE OF THE NEW MODE OF TALENT CULTIVATION}

\section{A. Building a new teaching system}

The characteristics with "platform + module" forms a scientific and reasonable curriculum system. The curriculum system of "platform + module" consists of 3 different levels: the basic platform, the professional basic platform and the professional direction. And four modules of knowledge structure include power series course module, application module, computer courses of mechanical series courses module, test module, control series courses of professional direction series courses, comprehensive practice course module (Fig.1).

Multidimensional progressive practice teaching system is applied[6,7]. "Multidimensional" is based on the engineering specialty characteristics, on the view of a macro perspective, from the four dimensions horizontally, the progressive training system, professional training, competition, project practice, and distribution to the undergraduate four years a total of eight semesters (Fig.2. Among them, the progressive experimental teaching system is composed of three levels: basic training, comprehensive training and general simulation training. The practice teaching links of several dimensions are coordinated and complement each other, so as to construct the multidimensional and three-dimensional practice teaching system that covers the first and the second classroom, and to improve the students' engineering specialty practice. Through the revision of personnel training programs, it reflects and teaching philosophy of measurement \& control specialty the formats the school characteristics with "thick foundation, wide professional, focusing on skills and looking for innovation".

\section{B. Construction of student centered teaching paradigm}

We promote fair, multi-level, diversified education, and use the new teaching mode and teaching method, teaching mode and method research and reform[8]. The current curriculum teaching is based on the group teaching and project driven teaching methods, but most of the courses still adopt the teacher centered teaching mode, as well as examination method is singleness, so as not to lead to teaching students in accordance with their aptitude. Consequently, adopting new teaching make students as the center, using hierarchical and modular teaching and project driven teaching, the combination of MOOC and face-to-face, also make corresponding assessment methods[9]. Grade teaching is a collective teaching as the basis, and structure a bridge between the two forms of collective teaching and individual teaching to achieve two complementary advantages, as well as to provide a fair and suitable for the individual development of the teaching environment and knowledge at different levels of students. As an innovative measure, graded teaching is a useful attempt and a powerful means of teaching reform. 


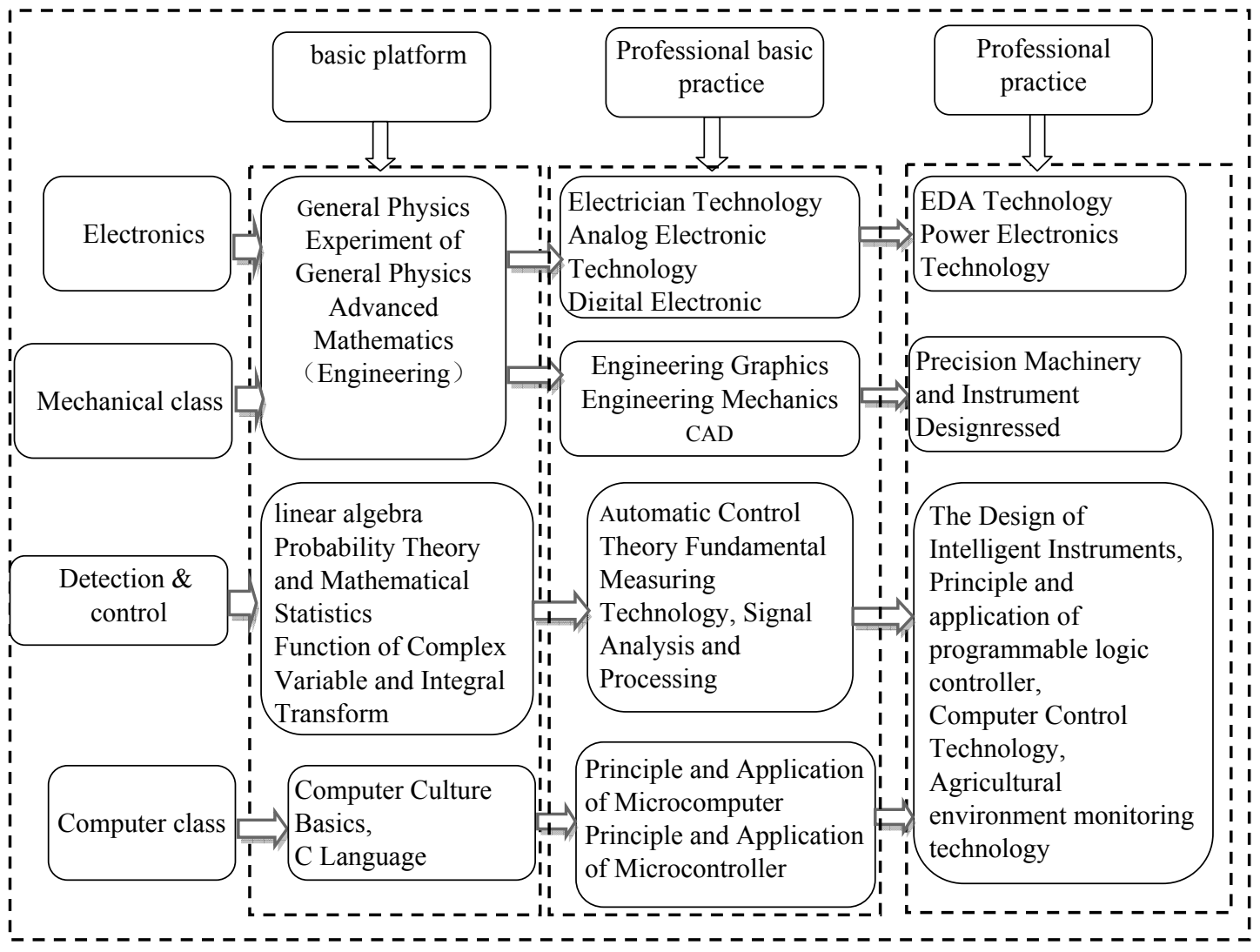

Fig. 1. Teaching system

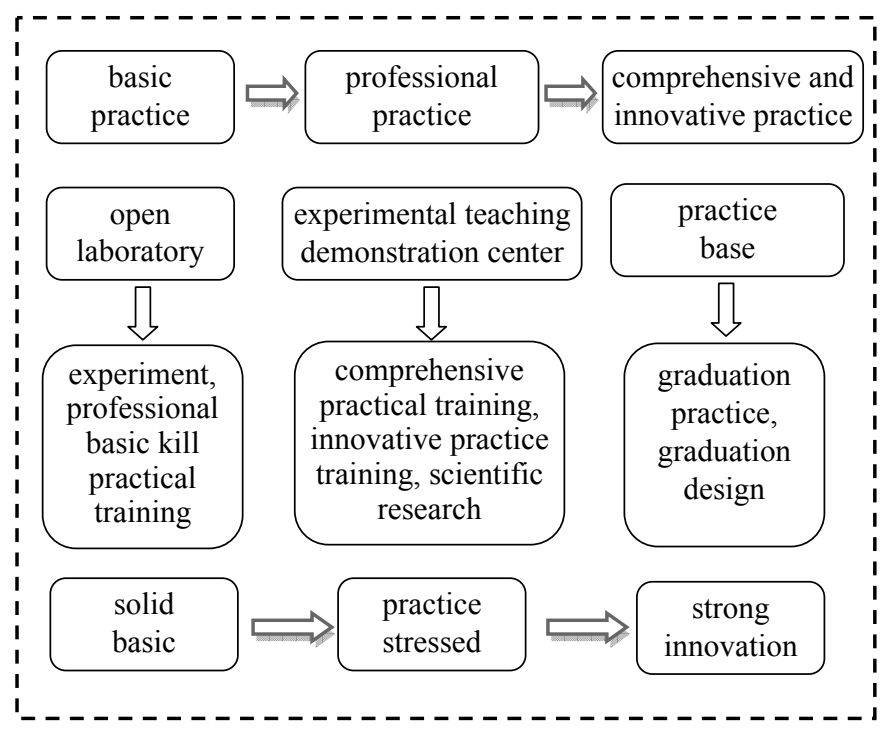

Fig. 2. Multidimensional progressive practice teaching system

\section{Construction of teachers' teaching support team}

Build up a team that takes core of academic leaders as the core, with young and middle-aged academic backbone as the main strength of ability and political integrity, optimized structure, reasonable age, the innovative spirit of the high level of teaching, and scientific research ability. First, improve the personnel training mechanism, encourage young teachers serving a $\mathrm{PhD}$, support young teachers reporting scientific research, academic research, participate in the domestic and foreign various academic exchange activities, in-depth business practice of enterprises, and improve the ability of scientific research. Secondly, to further strengthen the construction of backbone teachers. Organize key teachers to the base of teacher training approved by the Ministry of education or institutions to have professional theory and professional skills training; Establish a training system for relevant professional teachers to enterprise and take it as the title of conditions. Require teachers who apply for senior title to have half year exercise experience in enterprise to improve the teachers' practical teaching and innovative teaching level; Construct a "double team of teachers" teacher gradually.

\section{Enhancing students' practical ability of innovation and Entrepreneurship, starting from the characteristics of the school}

(1) Integrating "one guiding and the two driving" into the cultivation of students' ability

Take the discipline foundation, the practice teaching and the scientific research as the main line, integrate the "one guiding two driving" is into the process of personnel training. "One Guiding" is guided by the needs of society and industry, "two drives" is to stimulate students' interest in learning and stimulate students' ability of innovation and entrepreneurship. Adhere to the characteristics of running a school, in the study and practice, focus on cultivating students' active learning and lifelong learning awareness, and cultivate their creative thinking and innovation ability. 
Construct the teaching system of theory and practice. Strengthen the theory with practical application of multidimensional practice teaching system, strengthen practice teaching, pay attention to arouse the enthusiasm of students' active participation, comprehensive utilization and development of innovation, and cultivate students' practical ability, outstanding application characteristics.

(2) Adopting the project teaching method under the guidance system of undergraduate professional tutor to improve students' practical ability

Profession implementation undergraduate tutorial system and the professional mentors guide students to participate in scientific research and training activities, academic competitions and graduation design, etc. With the advantages of agricultural engineering specialty, integrate "the three integration" into the talent cultivation." Three integration" means a cross disciplinary integration of interdisciplinary, teaching and research practice integration, innovation and entrepreneurship education and professional education integration. Aim to solve the practical problems of the industry and agriculture, encourage students to participate in the project of teachers and students on the basis of scientific research projects, apply for innovation and entrepreneurship projects independently, as well as participate in various professional competitions and professional skills training, so as to enable students to master the knowledge of multi subject in practice, and enhance the ability of independent study, practice and innovation, at the same time, consolidate the basic knowledge, cultivate a certain production, management ability and cooperation ability.

\section{CONCLUSIONS}

As a new educational mode of higher education in China, the mode of innovation and entrepreneurship training has opened a new field for our education. The traditional mode of professional education cannot adapt to the social development and demand. Therefore, suitable talent cultivation program for development, which has been explored in practice of measurement \& control specialty in local agricultural Universities and is driven by the innovation, will inevitably encounter many problems restricting, but talent cultivation quality in the professional and innovation has made great progress, and will provide the reference to other brother universities with "transformation development". In future, the study on innovative talent cultivation mode of engineering specialty in local universities develops in the following three aspects: research on the value and connotation of innovation and entrepreneurship training mode; research on symmetry of control and responsibility of new talent cultivation mode; research on the curriculum system of optimizing and innovating talent cultivation mode with interconnection.

\section{ACKNOWLEDGMENT}

This work was financially supported by the Innovation and Entrepreneurship Training Reform Model Projects of Tianjin Agricultural University (20170813,20170201,20170416).

\section{REFERENCES}

[1] Miao Lu, Liu Zhongming. Research on Cultivation Applied Talents Mode of Agricultural Engineering Local Agricultural Colleges. Wisdom, 2017, 4:70. (In Chinese)

[2] Li Qiang. Exploration about the Current situation and Strategy of Applied talents training mode in local undergraduate colleges. The small and medium-sized enterprise management and technology,2017,6:127128.(In Chinese)

[3] Liu Zhikan,Zhao Feng,Zhang Zhiwei. The Exploration about the Training Mode for Innovation and Entrepreneurial Talents for Electronic Information Major Students in Local Universities: Current situation,Problems and Prospects. Higher Education Forum, 2016,1:3035.(In Chinese)

[4] Liu Yuan, Wu Haiyun, Shi Yu, Chang Ruokui, Li Chuanlin. Construction and exploration of teaching qualityassurance system in experiment center, 2016,19(4):182-187.(In Chinese)

[5] Su Xianchun. Research and practice of training mode of applied talents in local eng-ineering colleges. Journal of Jilin Institute of Chemical Technology, 2017,2:60-63.(In Chinese)

[6] Liu Yuan, Du Yanhong, Chang Ruokui, Liu Hua,Yu Yaping. The construction of multidimensional practical teaching system with the measurement and control specialty. Laboratory Science, 2012.15(6):140142.(In Chinese)

[7] Xu Fenghua, Wang Shenghuai, Zeng Wenhan, Li Tukun.Discussion and practice of innovative talents training mode in local undergraduate colleges. Education Modernization, 2017,1:3-5.(In Chinese)

[8] Tang Xiaohua, Lv Jingquan. The development of three-dimensional teaching resources and skills competition design in national skills competition[J]. Chinese Vocational and Technical Education, 2012, 35:81-84+88. (In Chinese)

[9] Cai Yanna, Xu Ziyuan. The MOOC development and application which transformed from the achievements of the SCM vocational skills competition [J]. Journal of Juamjusi Education Institute. 2016, 7: 220221. (In Chinese) 